Erikson, D. (1955). J. gen. Microbiol. 13, 127-135

\title{
Thermoduric Properties of Nocardia sebivorans and other Pathogenic Aerobic Actinomycetes
}

\author{
BY DAGNY ERIKSON \\ Bacteriology Department, University of Aberdeen
}

SUMMARY: The pathogenic partially acid-fast lipophilic organism Nocardia sebivorans and a closely allied species were found capable of withstanding exposure to $90^{\circ}$ for $10 \mathrm{~min}$. when dispersed in phosphate buffer suspensions in small sealed ampoules. Denser suspensions withstood $3 \mathrm{~min}$. at $100^{\circ}$. The nature of the medium on which the cells were grown did not seem to influence their thermoduric properties. Of the two morphotypes of $N$. sebivorans that were originally isolated, one (G) consistently showed a higher degree of heat-resistance. The morphotypes were further distinguished by slight differences in the 'feel' of the cells and in their response to micromanipulative procedures. Different single cell isolates of the two morphotypes varied as regards thermotolerance, but the more resistant were $G$ isolates. The lag period following heat treatment was generally accompanied by a compressed and stunted mode of growth, featuring prolonged angular division. Subsequent growth was normal.

Two strains of the pathogenic Streptomyces madurae, as well as two saprophytic soil species of Nocardia, were killed by exposures of 1-2 min. at $65^{\circ}$. An organism received as a blood culture and belonging to the Streptomyces albus group, was able to withstand $90^{\circ}$ for $1 \mathrm{~min}$. Subjection to heat treatment increased the inherent autolytic tendency of the culture and affected the type of sporophores produced during the first generation.

Apart from the true thermophilic organisms, which so far have been reported only within the genera Micromonospora (or Thermoactinomyces Tsiklinsky) and Streptomyces, the actinomycetes in general have been found to possess little resistance to heat. Waksman, Umbreit \& Cordon (1939) tested over one hundred mesophilic sporing streptomycetes and found that the majority were killed by short exposures to temperatures as moderate as $50^{\circ}$, and that there was in fact a physiological line of demarcation between those strains capable of living at elevated temperatures and the common run of ordinary streptomycetes isolated from composts, soil and other natural products. Other investigators have agreed that typical streptomycete spores differ from eubacterial spores in their lack of heat-resistance.

Few attempts have been made to test the thermotolerance of non-sporing representatives of the genus Nocardia. Sforza $(1940,1946)$ in Ethiopia described under the generic name Asteroides Leonardi \& Puntoni several organisms isolated from cattle farcy and mastitis, which appear very similar to members of the species-groups Nocardia farcinica and $N$. asteroides. Certain of these pathogens, notably Asteroides granulosus Sforza, were capable of withstanding $60-65^{\circ}$ for $30 \mathrm{~min}$. when dispersed in sterile milk. They were therefore able to survive certain pasteurization processes. Gorrill \& Heptinstall (1954) noted the ability of Nocardia sebivorans, an organism pathogenic to 
experimental animals, to withstand $60^{\circ}$ for $30 \mathrm{~min}$. Both $N$. sebivorans and the organism described by Sforza are partially or entirely acid-fast, and belong to the more stable or 'hard' mycelial section of the genus Nocardia. N. sebivorans is a lipophilic organism, utilizing paraffin and other fatty substances, and produces a relatively abundant aerial mycelium. In these respects it compares with $N$. paraffinae, a common soil saprophyte. These firm-textured, well-ramified species producing considerable aerial growth (Ørskov, 1923, group II $a$ ) have the closest morphological affinities with the genus Streptomyces. On the other hand, those streptomycetes which have lost their power to produce aerial mycelium can readily be confused with species of Nocardia until a more careful examination is made (cf. Waksman, 1953, p. 1).

In the present work the thermoduric properties of single cell isolates of two morphotypes of Nocardia sebivorans were tested and compared with those of a closely related form (strain El1, isolated by Dr Elek of St George's Hospital Medical School, London, from a fatal case of meningitis). N. paraffinae (NCTC no. 3422) and an allied form (strain BSN, isolated by Dr D. M. Webley, Macaulay Institute for Soil Research, from beach sand) were included in the preliminary tests, but failed to show sufficient degree of thermotolerance to justify continued study. In addition, three cultures of streptomycetes from morbid material were tested: two strains of Streptomyces madurae (Th/1 and Th/2, isolated by Major Altmann of Tel Hashomer Hospital, Israel, from mycetoma of the foot); and a form of $S$. albus (no. 1569, also isolated by Major Altmann from blood), which resembled an organism (NCTC 4572) described by Erikson (1935) as Actinomyces bovis Harz var. nigerianus. All three cultures were non-acid-fast and proteolytic, thus differing essentially from the nocardial species. The two strains of Streptomyces madurae produced very little aerial mycelium and that only on simple substrates, and failed to show any high degree of thermotolerance. S. albus 1569 readily sporulated and was found more suitable for testing in conjunction with Nocardia sebivorans. This organism also possessed autolytic properties.

\section{ME'THODS}

Fifteen single-cell isolates of Nocardia sebivorans were prepared according to the methods of Erikson \& Masson (1954): six from the morphotype G ( $\mathrm{scm}$, vi, mb, mg, lmg, sg); and nine from the morphotype $W(2 a 1, a, 3, b, 22, c, 31$, d, 1). Descriptions of the original morphotypes are given by Erikson in an addendum to Gorrill \& Heptinstall (1954).

Cells for heat testing were harvested from the various isolates of Nocardia sebivorans and of strain El 1 as follows: washings were taken from 3-, 5-, 7and 10-day growths on: $(a)$ nutrient agar slopes; $(b)$ surface of nutrient broth in $1 \mathrm{oz}$. stoppered bottles; $(c)$ cellophan over nutrient agar in poured plates. They were then shaken in phosphate buffer, lightly spun, and relatively smooth suspensions prepared in the manner described by Webley (1954a) for Micromonospora vulgaris. Preliminary thermal death-rate experiments, using dilute suspensions in sealed ampoules in the manner previously used for the 
thermophilic micromonosporas (Erikson, 1952), yielded such irregular results as to make it clear that the samples of the suspensions employed were not comparable as regards their content of thermotolerant cell elements. This was the case whatever the age of the culture on the complex nutrient stock medium, and variations in the technique of preparing the suspensions made little difference. Accordingly, much denser suspensions were employed than in the case of the spore-bearing thermophile.

Isolates of Nocardia sebivorans and of strain El1 were also grown in an ammonium phosphate + Czapek salt basal medium with the addition of solid or liquid paraffin, or with the $\mathrm{Na}$ salts of valeric, caprylic or butyric acids. Growth was good but slow in most cases, and such media could not compare with the stock nutrient agar or broth for the purpose of collecting cells. Suspensions were made from a set of 2-month old cultures with solid paraffin as the source of carbon.

The following procedures were adopted: in the case of growths under conditions $(a)$ and $(c)$, either two well-grown slopes or one cellophan circle yielded sufficient material for $10 \mathrm{ml}$. of phosphate suspension to be subdivided in $0.5 \mathrm{ml}$. lots in sealed ampoules; in the case of growth under condition $(b)$, the surface growth from a $1 \mathrm{oz}$. bottle was resuspended in $2 \mathrm{ml}$. phosphate buffer, and a separate bottle employed for each heat test. The sealed ampoules were totally immersed in a water-bath, and heated for 1-10 min. at temperatures rising in $5^{\circ}$ steps from $60^{\circ}$ to $95^{\circ}$. The $1 \mathrm{oz}$. bottles containing primary suspensions were heated at $100^{\circ}$ in a steamer for the same times. Allowance was made for the time taken for the contents of the vessels to reach the desired temperature, and at the expiry of the period of heating all vessels were placed in ice. The contents were then removed to sterile Durham tubes, centrifuged to remove the suspending fluid, and $\mathbf{0 . 5} \mathrm{ml}$. (or $2 \mathrm{ml}$. in the case of the screwcapped bottles) of a starch $(1 \%)+$ casein hydrolysate $(0 \cdot 1 \%)+$ Czapek salts medium added. It was found that this medium was superior to nutrient broth in yielding a consistently higher proportion of survivors. The duplicate unheated controls were treated in the same way.

The cultures Streptomyces madurae ( $\mathrm{Th} / 1$ and $\mathrm{Th} / 2$ ) and $S$. albus 1569 grew more slowly than the nocardial species and in the typical compact strepto. mycete fashion which made their dispersion more difficult. They were employed only in dense primary suspensions in small bottles, as described above. The sporulating $S$. albus 1569 was subject to autolysis on rich media. This was less evident when starch was incorporated in the medium. The CPS medium employed for the thermophilic micromonosporas (Erikson, 1952) was found suitable for the cultivation of all three organisms.

Slide cultures were prepared from the heated and unheated suspensions in the same way as for the germination of heat-resistant spores of Micromonospora vulgaris (Erikson, 1955). The mode of growth was observed directly at frequent intervals by means of phase-contrast microscopy. Representative sets of heated cultures in Durham tubes were also removed at intervals during the course of incubation, and the cells stored in $5 \%$ neutral formalin. Incubation throughout was at $37^{\circ}$ except for strain BSN and Nocardia paraffinae $\left(20-23^{\circ}\right)$. 


\section{RESULTS}

\section{Thermotolerance of different species}

Nocardia sebivorans and strain El1 withstood a maximum exposure of $10 \mathrm{~min}$. at $90^{\circ}$ when dispersed in $0.5 \mathrm{ml}$. lots in small sealed ampoules, and of $3 \mathrm{~min}$. at $100^{\circ}$ in denser suspensions in screw-capped bottles. Survivors were obtained from mature growths on nutrient broth, nutrient agar, and the various ammonium salt media with fatty acids or paraffin added. The maximum tolerated exposure for Streptomyces albus 1569 was $90^{\circ}$ for $1 \mathrm{~min}$. The two strains of $S$. madurae were much less resistant, their maximum being 1-2 min. at $60^{\circ}$. A similar degree of thermotolerance was shown by the soil saprophytes BSN and Nocardia paraffinae, which survived 1-2 min. at $60^{\circ}$ but were killed by $1-2 \mathrm{~min}$. at $65^{\circ}$.

\section{Thermotolerance of different isolates of Nocardia sebivorans}

It was stated earlier (Erikson, in addendum to Gorrill \& Heptinstall, 1954) that two distinct morphotypes appeared spontaneously within this culture when first studied. On the original rich complex organic media on which they appeared the two types were macroscopically distinct; $W$ constantly produced a prolific aerial mycelium which made the colonies seem chalky white ( $\mathrm{Pl} . \mathbf{1}$, fig. 1), whereas the aerial growth of $\mathrm{G}$ was much less developed giving a grey aspect to the culture. These distinctions persisted after animal passage, although no qualitative difference could be found between the lesions induced by the two growth-forms.

Such gross visible differences in growth-form were not very marked after the two types had been maintained for some time on simpler media, although a readier development of aerial mycelium could usually be detected on the part of $\mathrm{W}$ when growing in microculture (see Pl. 1, fig. 6). Moreover, during the processes of micromanipulation (Erikson \& Masson, 1954) it was repeatedly found that there were perceptible differences in the behaviour, refractibility, and 'feel' of the cells of $\mathbf{G}$ and W. Thus G cells from nutrient broth cultures were difficult to see in micro-droplets, proved almost intractable by appearing to have a surface coating that resisted seizure by micro-instruments, and were pronouncedly lipophilic-large numbers passing rapidly into the oil phase. This was also the case, although to a lesser extent, even when they had been cultivated for several subcultures in an aqueous Czapek glucose nitrate medium, whereas such treatment tended to render the $W$ cells very much more manageable.

Again, while both $\mathrm{G}$ and $\mathrm{W}$ isolates were capable of growing in droplets of Czapek mineral medium oil without added carbon source and of extending their filaments into the surrounding oil of a de Fonbrune paraffin oil micromanipulating chamber, the more vigorously growing $\mathbf{W}$ isolates were more consistent in producing a clearly marked zone of gas bubbles in the oil ( $\mathrm{Pl} .1$, fig. 9). That these bubbles were not air bubbles introduced with the droplet of medium was proved by repeated careful experiment. This phenomenon was 
of unusual interest, since visible gas production is very rare among actinomycetes. The G morphotype, partly perhaps because it did not grow so well in these circumstances and passed into the oil phase earlier and more completely, seldom produced this display of bubbles. When an immersion oil (polyric oil-see Erikson \& Masson, 1954) was substituted for paraffin, the bubbles were not apparent even in the case of $\mathrm{W}$ and the filamentous growth was noticeably more elongated.

These slight distinctions between the $\mathrm{G}$ and $\mathrm{W}$ types were borne out by variations in their responses to heat treatment. Since the early production of an aerial mycelium by the surface growth on liquid media is a group characteristic of this type of nocardia (see Erikson, 1935), the time taken for its appearance after the heating of the cells was regarded as an index of recovery on the part of each isolate. Thus when three $\mathbf{G}$ and three $\mathbf{W}$ isolates, together with some strain El 1 organisms, were heated for $3 \mathrm{~min}$. at $70^{\circ}, 85^{\circ}$ and $100^{\circ}$, respectively, surface growth with aerial mycelium appeared after 2 days of incubation in strain G/Img and to a lesser extent in strain G/sg in the $85^{\circ}$ series; after 3 days with the same two isolates in the $100^{\circ}$ series; and it was not until after 7-10 days of incubation that the bottom growth in strains El1 and W/22 gave rise to surface growth with aerial mycelium in the $100^{\circ}$ series. In the control series, typical surface growth regularly appeared within one day.

As was pointed out in Methods, quantitative measurements were not readily applicable to the suspensions used for these heat tests. In practice it was found that the most consistent results were obtained when the heated suspension was distributed in a number of small Durham tubes and relative comparisons made over a large number of tubes. Few differences could be detected in the survival capacities of the different isolates for exposures up to 3-5 min. at $70^{\circ}$, but thereafter strain G/lmg constantly showed surface growth before the other isolates. In all the tests three $\mathbf{G}$ isolates (lmg, sg, vi) survived exposure to the more elevated temperatures more frequently than any of the $\mathrm{W}$ isolates.

\section{Mode of growth of heated and unheated cells of \\ Nocardia sebivorans and other nocardias}

As will be seen from Pl. 1, fig. 1, mature growth of the W strain of Nocardia sebivorans is as a rule so well covered with aerial mycelium that suspensions of cells washed from the surface will consist mainly of the components of that aerial covering. The characteristic angular fashion in which these aerial strands develop in maturity is shown in the impression preparations of strains G/sg and El 1 in Pl. 1, figs. 2 and 3, respectively. Segmentation within the long filaments is visible in $\mathrm{Pl}$. 1, fig. 2, and many of the fragmented cylindrical cells can be seen in Pl. 1, fig. 3. The germination of these cells as of other mycelial fragments follows the nocardial pattern (Ørskov, 1923; Erikson, 1935; McClung, 1949). Swelling of the primary cell is followed by extrusion of a short tube which often immediately changes its orientation before segmenting or branching, while at the obtuse angle so formed the primary cell 
may develop one or more large round cells. Each of these round cells may behave in a similar fashion with the result that there is an outstanding impression of polymorphy and of short cells in angular apposition during the early stages of growth (see Pl. 1, fig. 4). In the subsequent stages under normal conditions this appearance gives place to the typical branching mycelium of an actinomycete (Pl. 1, fig. 5), but with the early development of aerial buds from the segmented filaments an angular aspect may again be introduced ( $\mathrm{Pl}$. 1, fig. 6). Prolongation of this angular mode of development was found to be a feature of the lag period which followed heat treatment of the cells. The samples of 2-day bottom growth shown in Pl. 1, fig. 7, illustrate the tardy development of cells which repeatedly changed their orientation with each subdivision and which seemed to suffer from inhibition of the factor which permitted undeviating growth along one axis resulting in filaments. The cells giving rise to this growth were subjected to the upper limit of heat treatment: $100^{\circ}$ for $3 \mathrm{~min}$.

These phenomena were found in general in the early stages of development of cells which had been held at temperatures of $75^{\circ}$ and over. The deleterious effect of this heat treatment did not appear to be permanent, and on prolonged incubation luxuriant surface growth with characteristic aerial mycelium was obtained with all survivors, although this might sometimes require as long as 7-10 days. With the less drastically heated cells $\left(60^{\circ}\right.$ for $15 \mathrm{~min}$.) there was often little difference to be found in the mode of growth of the heated cells (Pl. 1, fig. 11) compared with that of the control (Pl. 2, fig. 12). After exposure to intermediate temperatures (e.g. $80^{\circ}$ for $1 \mathrm{~min}$.), there was often a more prolonged persistence of the short round cells (Pl. 2, fig. 13, bottom right-hand), which commonly occur only during the initial stages of growth (cf. Pl. 1, fig. 4).

Abnormally large round, hexagonal, clavate, or quite irregular cells with thickened walls (Pl. 1, fig. 8) appeared in paraffin wax cultures and also on $n$-dodecane (cf. with growth of Nocardia opaca on waxes, etc.: Webley, 1954b). No enhancement of heat resistance was shown as the result of culturing $N$. sebivorans and strain El1 on these fatty substances; and therefore no attempt was made to defat the cells before heating. The grotesque cells were proved viable and capable of producing normal growth when seeded on to the surface of slide cultures with ordinary media.

Preliminary tests with the two saprophytic soil species revealed only a limited degree of thermotolerance $-60^{\circ}$ for $1-2 \mathrm{~min}$. It should, however, be borne in mind that their optimum temperature for growth was $19-23^{\circ}$, as against $37^{\circ}$ for the pathogenic species. Neither Nocardia paraffinae nor strain BSN lost the capacity of producing aerial growth when subjected to this moderate degree of heat (Pl. 1, fig. 10), and the chief response was that of retardation of growth.

\section{Mode of growth of heated and unheated Streptomyces albus 1569}

In its early mycelial stages Streptomyces albus constantly showed the characteristic uniformity of a streptomycete as regards filament width and monopodial branching. In $\mathrm{Pl} .2$, fig. 14, it will be noted that in several places 
the filaments approaching from neighbouring growths turn away from one another and that, as Erikson (1949) stressed, there are no clear cases of anastomosis in the vegetative mycelium. The characteristics of the subsequent aerial growth were tightly coiled sporophores (Pl. 2, fig. 16) on a good agar medium such as CPS, but with long straight interconnecting strands between the growths (Pl. 2, fig. 15). The tight spirals became rarer and straight sporechains more common in the surface growth on liquid media of simpler composition, e.g. $5 \%$ casein digest with different sugars (Pl. 2, figs. 17-19).

Subjection to heat treatment emphasized the inherent tendency of the organism towards autolytic disintegration. An extreme degree of segmentation (Pl. 2, fig. 20) followed by partial autolysis was frequently seen in the 1- to 3-day vegetative growths on slide cultures which had been sown with cells heated for $1 \mathrm{~min}$. at $80^{\circ}$. Similar cells were able to produce normal surface growth in liquid media, but when they were heated for 1 min. at $100^{\circ}$ only bottom growth of the puffball colony type appeared in the course of 3 days. Then on the fifth or sixth day the survivors (usually only 1-2 colonies/tube) were no longer visible because of autolysis. Yet some of the mycelial fragments remained viable although the liquid generally appeared quite clear, for when this was added to fresh medium normal growth very slowly (15-20 days) developed again.

The aerial growth produced after exposures to $80^{\circ}$ for $1 \mathrm{~min}$. (the upper limit for the production of surface growth after heat treatment) was generally short and straight, and the sporophores were often sterile. When the exposure was more moderate, e.g. $60^{\circ}$ for 1-5 min., normal spiral sporophores were frequently produced. None of the abnormalities noted after heat treatment persisted in subculture.

\section{DISCUSSION}

From a phylogenetical point of view the most interesting findings in this work were that the nature of the injury due to heat varied with the type of organism heated, and that in each case there was temporary loss of the ability to produce a complex morphological structure characteristic of the particular organism. In the case of the heated Nocardia sebivorans organisms, inhibition of aerial mycelium production combined with a prolonged angular development of the vegetative mycelium resulted in growths morphologically similar to those of less developed nocardial species in a different systemic subdivision. The differences in thermotolerance between the two morphotypes seemed correlated with slight variations in the rate of growth and properties of the external membranes of the entire organism and could not be attributed to any particular types of cells. It was noteworthy that none of the thick-walled polymorphous cells produced on media containing waxy substances showed any superior resistance to heat.

In the case of the sporing Streptomyces albus, the effect of heat on the production of aerial mycelium was complicated by enhancement of the autolytic tendency of the strain. Yet a similar patter prevailed. Instead of spiral sporophores-the most advanced type of structure-straight aerial filaments, 
similar to those produced normally on certain poorer media, were commonly obtained after heat treatment. Often these sparse aerial filaments were sterile, and when accompanied by an extreme degree of segmentation of the vegetative mycelium the entire cell complex resembled that of a nocardial type.

This work was done by the author as a member of the scientific staff of the Agricultural Research Council. I am indebted to Professor J. Cruickshank, C.B.E., for the hospitality of his department; Miss F. M. Masson of the Rowett Research Institute for Animal Nutrition for help with the micromanipulations; and Miss Mildred Mackay for technical assistance.

\section{REFERENCES}

Erikson, D. (1935). The pathogenic aerobic organisms of the Actinomyces group. Spec. Rep. Ser. med. Res. Coun., Lond. no. 203.

Erikson, D. (1949). The morphology, cytology, and taxonomy of the actinomycetes. Annu. Rev. Microbiol. 3, 23.

Erikson, D. (1952). Temperature/growth relationships of a thermophilic actinomycete, Micromonospora vulgaris. J. gen. Microbiol. 6, 286.

Erikson, D. (1955). Changes in refractility and permeability accompanying germination of heat-resistant spores of Micromonospora vulgaris. J. gen. Microbiol. 13, 119.

Erikson, D. \& MASSON, F. M. (1954). Modifications of micromanipulative practice suitable for single cell isolation and cultivation of $(a)$ aerobic and transiently chain-forming, (b) lipophilic, and (c) microaerophilic bacteria. J. gen. Microbiol. $11,209$.

Gorrill, R. H. \& Heptinstall, R. G., with an Addendum by Erikson, D. (1954). The animal pathogenicity of Nocardia sebivorans, n.sp. J. Path. Bact. 68, 387.

McClung, N. M. (1949). Morphological studies in the genus Nocardia. Lloydia, 12, 137.

Ønskov, J. (1923). Investigations into the Morphology of the Ray Fungi. Copenhagen: Levin and Munksgaard.

SForza, M. (1940). Studio di alcuni acidoresistenti (actinomiceti-micobatteri) isolati da lesioni pseudo-attinomicotiche e tubercolari di bovini in Eritrea. Nuova Vet. 18, 5.

Sforza, M. (1946). Segnalazione di mastiti da Asteroides e prove di pastorizzazione del latte inquinato con tali germi. Boll. Soc. ital. Med., Sez. Eritrea, 6, 3.

Waksman, S. A. (1953). The Actinomycetes: Part I in Guide to the Classification and Identification of the Actinomycetes and their Antibiotics. Baltimore: Williams and Wilkins.

Waksman, S. A., Umbreit, W. W. \& Cordon, T. C. (1939). Thermophilic actinomycetes and fungi in soils and in composts. Soil Sci. 47, 37.

WebLey, D. M. $(1954 a)$. The effect of oxygen on the growth and metabolism of the aerobic thermophilic actinomycete Micromonospora vulgaris. J. gen. Microbiol. $11,114$.

Webley, D. M. (1954b). The morphology of Nocardia opaca Waksman \& Henrici (Proactinomyces opacus Jensen) when grown on hydrocarbons, vegetable oils, fatty acids and related substances. J. gen. Microbiol. 11, 420. 
Journal of General Microbiology. Vol. 13. No. 1
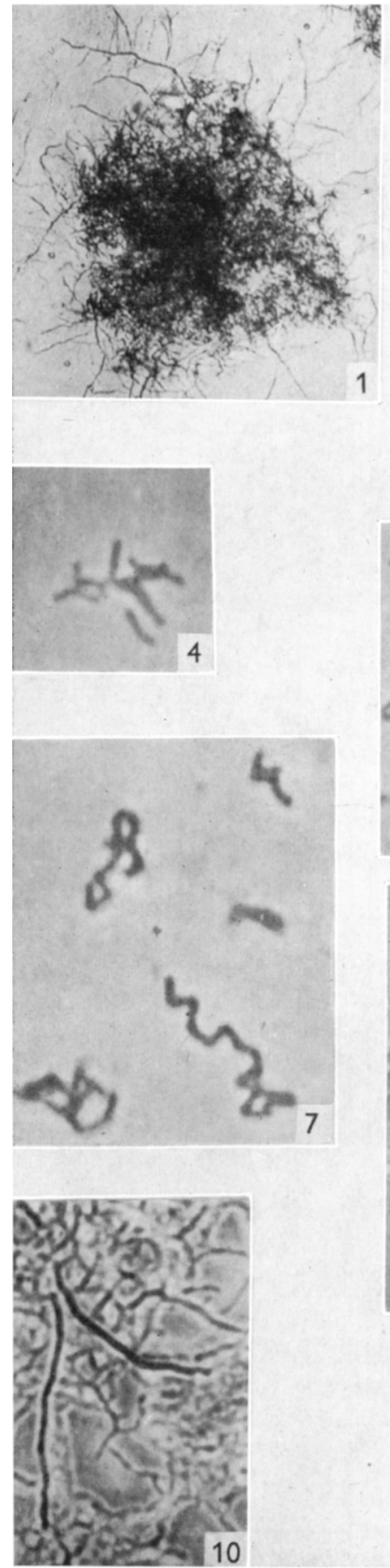
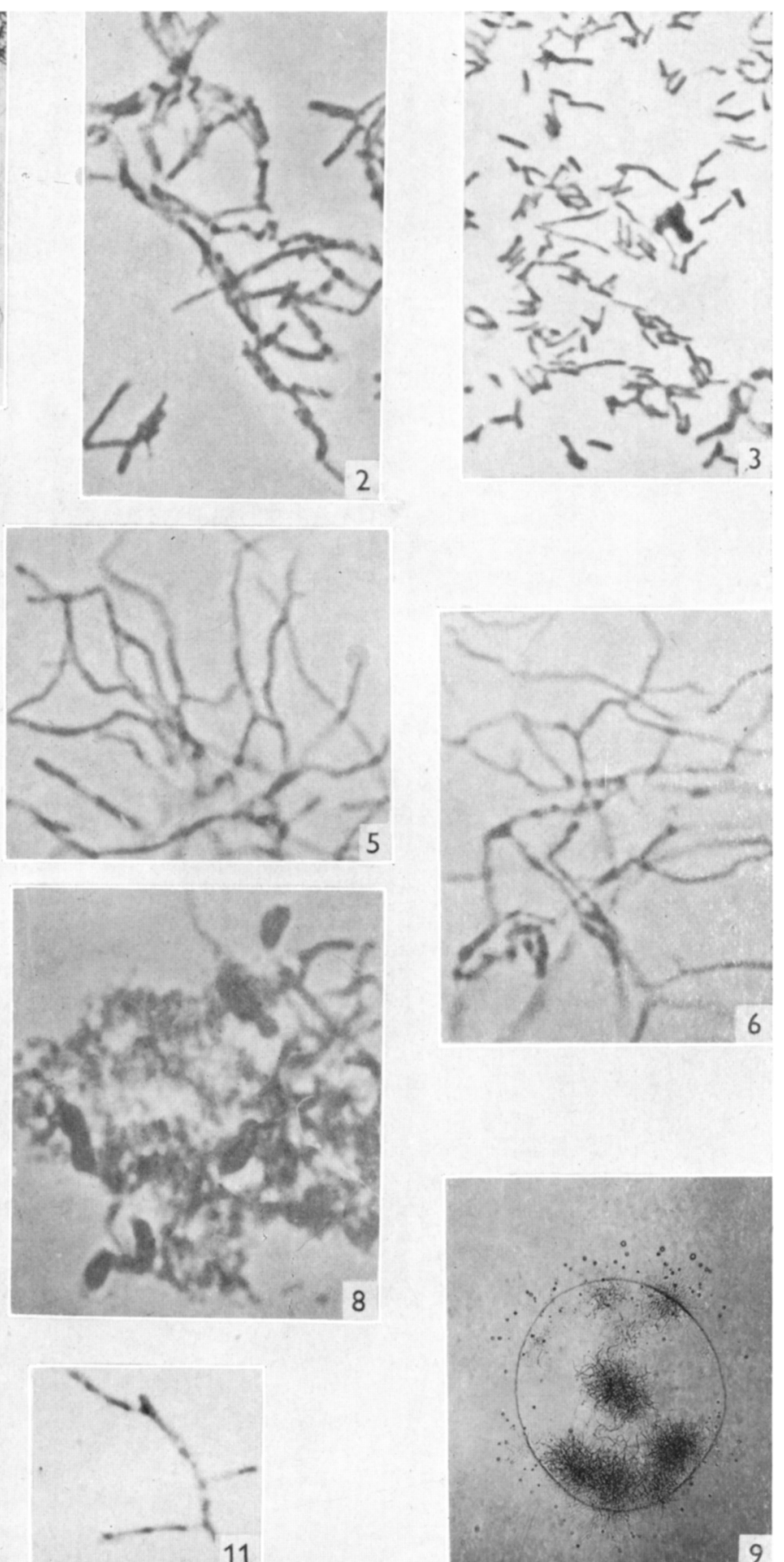

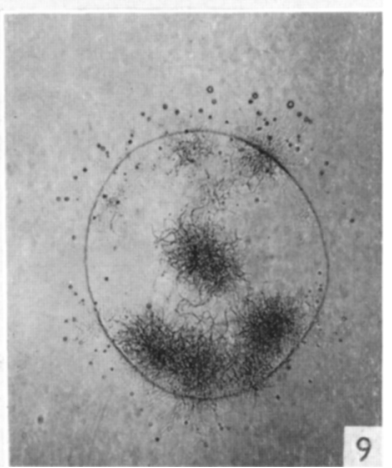

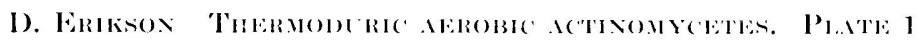


Journal of General Microbiology, Vol. 13, No. 1
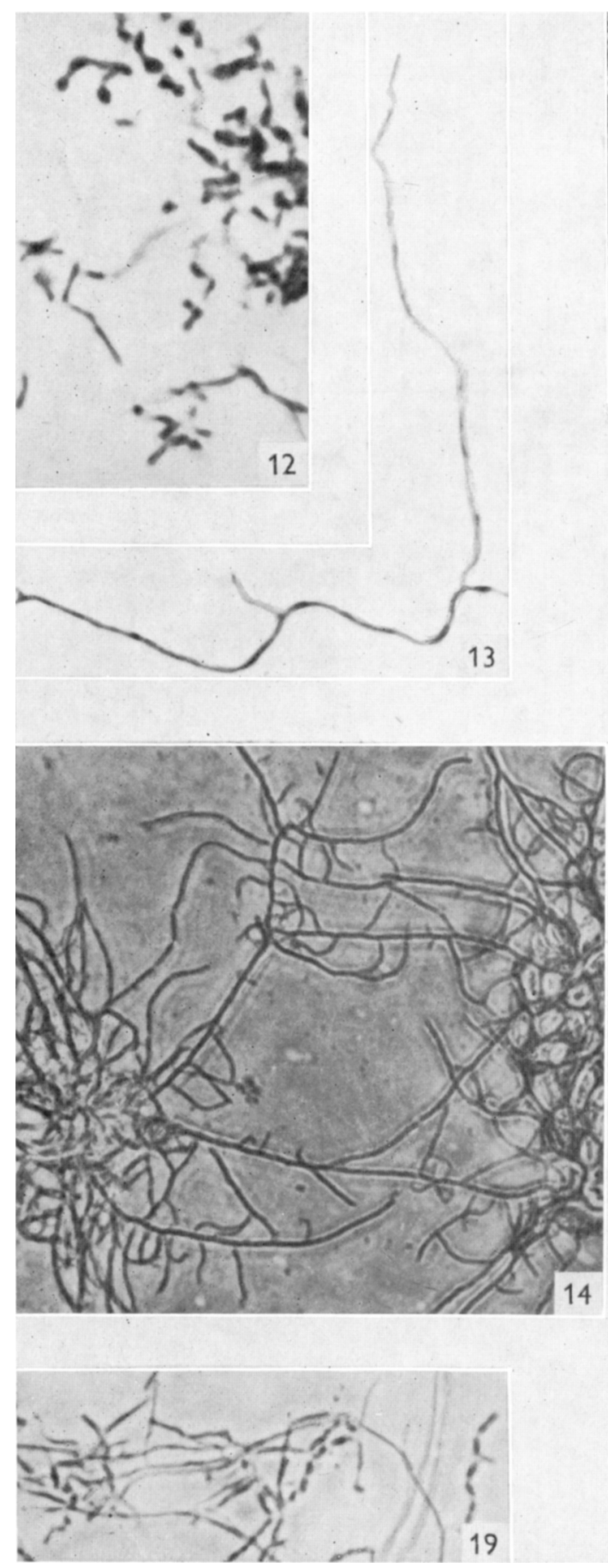
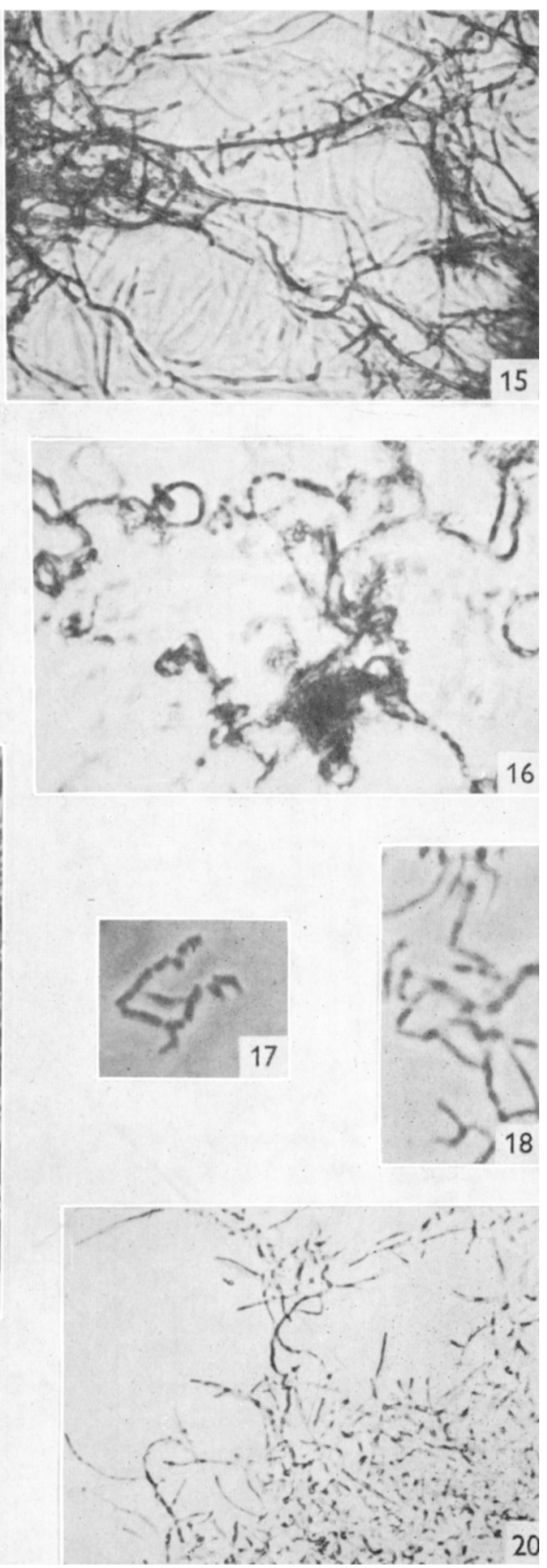

D. Erikson-Thermoduric aerobic actinomycetes. Plate 2 


\section{EXPLANATION OF PLATES}

Phase-contrast preparations unless otherwise stated.

Plate 1

Fig. 1. Mature colonies of Nocardia sebivorans (type W) with good development of aerial mycelium. $(\times 150$.

Fig. 2. Impression preparation of mature aerial mycelium, strain $\mathrm{G} / \mathrm{sg}, 2$ weeks on nutrient agar, showing angular development of aerial strands and advanced stage of segmentation. $(\times 2160$. $)$

Fig. 3. Impression preparation of aerial growth, 2 weeks on nutrient agar, strain El1, fragmented cells, many still showing angular division. $(\times \mathbf{2 1 6 0}$. $)$

Fig. 4. Slide culture, $16 \mathrm{hr}$. on nutrient agar, strain $\mathrm{G} / \mathrm{mb}$, showing swollen primary cells and change of orientation in young filaments. $(\times \mathbf{2 1 6 0 .})$

Fig. 5. Young typical branching mycelium, strain $\mathrm{W} / 1,24 \mathrm{hr}$. on nutrient agar. $(\times 1195$.

Fig. 6. Another portion of same specimen as in fig. 5 , showing segmentation of filaments and early development of serial buds, giving angular aspect to growth. $(\times 1195$.

Fig. 7. Strain El 1, incubated for $48 \mathrm{hr}$. in starch casein hydrolysate liquid, after heating at $100^{\circ}$ for 3 min., showing slow growth and marked angular development. $(\times 2160$.

Fig. 8. Strain El1, 2 months on ammonium phosphate paraffin wax showing large clavate cells and normal filaments attached to fragment of paraffin wax. $(\times \mathbf{2 1 6 0}$.)

Fig. 9. Droplet of Czapek salts, without added carbon source, in paraffin oil chamber of micromanipulating slide, strain $W / 1$, after 3 days' incubation, containing several colonies derived from pool of short cell elements, demonstrating zone of gas bubbles in oil phase. $(\times 60$.) Photograph by Miss F. M. Masson.

Fig. 10. Strain BSN, grown at room temperature for 3 days after heating for $1 \mathrm{~min}$. at $60^{\circ}$, showing segmenting growth on cellophan over nutrient agar, with two aerial filaments arising from centre of growth. $(\times 1195$. $)$

Fig. 11. Strain W/1, 24 hr. incubation at $37^{\circ}$ after $15 \mathrm{~min}$. at $60^{\circ}$. Slender branching filaments.

\section{Plate 2}

Fig. 12. Strain El 1, 24, hr. incubation at $37^{\circ}$ after 1 min. at $80^{\circ}$. Multiplication of short irregular cells. $(\times 1195$.

Fig. 13. Strain $\mathrm{W} / 1,24 \mathrm{hr}$. incubation at $37^{\circ}$ of unheated control. Very long slender branching filaments arising from primary cell. $(\times 1195$.

Fig. 14. Streptomyces albus 1569 . $24 \mathrm{hr}$. on cellophan over CPS agar. Ramifying mycelia with tips of filaments frequently turning away from adjacent flaments. $(\times 930$. $)$

Fig. 15. Another portion of growth in fig. 14, after 3 days, showing straight interconnecting aerial strands between the colonies. $(\times 930$.)

Fig. 16. Slide culture of 1569,1 week on CPS agar showing individual coiled sporophores. $(\times 1195$.

Fig. 17. Sporulating surface growth of 1569 in liquid glucose casein digest, 2 weeks, showing portion of loose spiral. $(\times \mathbf{2 1 6 0})$

Fig. 18. Similar sporulating growth from surface of starch casein digest liquid medium, 2 weeks. Tightly coiled spiral sporophores rarer. $(\times 2160$. $)$

Fig. 19. Sporulating surface growth from melibiose casein digest medium, 2 weeks. Many long and mostly straight spore chains. Lightly stained with dilute toluidine blue. $(\times 2160$.

Fig. 20. Vegetative growth, 2 days on cellophan over CPS agar after 1 min. at $80^{\circ}$. Extreme degree of segmentation in entire mycelium. $(\times 720$. 